\title{
POLÍTICA CRIMINAL PETISTA E SUA LEITURA CRIMINOLÓGICA (1979-2002)*
}

Ícaro Del Rio Pertence Gomes **

Resumo: O objetivo deste artigo é debater a política criminal petista (programa que estabelece as condutas que devem ser consideradas crimes e as políticas públicas para sua repressão e prevenção) e a leitura criminológica (apreensão das principais determinantes das condutas criminosas) que a embasa. Para tanto, analisaram-se os documentos redigidos pelo conjunto do partido durante o período de 1979 a 2002. Estes documentos trazem cinco grandes eixos para a questão criminal brasileira: (i) "Criminalidade" urbana; (ii) Crimes políticos rurais; (iii) "Corrupção"; (iv) Criminalização das opressões e (v) Defesa dos direitos humanos e reforma dos aparelhos repressores do Estado. Em linhas gerais, quando lê-se que o crime é uma prática de certa camada privilegiada, o partido denuncia a impunidade sistêmica desses agentes e conclama a apuração e punição destas condutas, criando-se aparatos e reformando os já existentes para tanto. Quando o crime é um "meio anti-social de sobrevivência" das classes espoliadas, compreende-se que a política econômica é a responsável por pressionar os trabalhadores a tais condutas e a proposta principal é elevar as condições materiais dos trabalhadores para que possam sobreviver através de meios lícitos. A exceção a tal tendência são os atos de racismo, machismo e homofobia que atravessam todas as classes sociais. Neste caso, conclama-se a punição destas condutas, ante sua impunidade, bem como a criação de um aparato de proteção do Estado. Por fim, o partido é enfático em defender a reforma do sistema prisional e de todo o aparato repressivo do Estado em defesa dos direitos humanos.

Palavras-chave: Partido dos Trabalhadores; Política criminal; Programa; Criminologia.

\section{Partido dos Trabalhadores' AGENDA ON CRIME (1979-2002)}

\begin{abstract}
The objective of this article is to debate the Partido dos Trabalhadores' criminal policy (a program that establishes the behaviors that should be considered crimes and the public policies for its repression and prevention) and its criminological basis (apprehension of the main determinants of criminal behavior) The documents written by the party as a whole during the period from 1979 to 2002 were analyzed. They bring five main topic to the Brazilian criminal issue: (i) Urban "criminality"; (ii) Rural political crimes; (iii) "Corruption"; (iv) Criminalization of oppressions on social minorities; (v) Defense of human rights and reform of the State's repressive apparatus. Synthetically, when it is understood that crime is a practice of a certain privileged social layer, the party denounces the systemic impunity and calls for the investigation and their punishment, creating apparatuses and reforms. When crime is an "anti-social mean of survival", the party claims that the economic policy is responsible for pressuring workers to such behavior and the main proposal is to

\footnotetext{
* Este artigo é fruto do projeto de Iniciação Científica Voluntária intitulado: Política criminal do Partido dos Trabalhadores e perda de perspectiva das classes trabalhadoras (1980-2002), administrado pela Pró- Reitoria de Pesquisa, de 23/04/2020 à 24/03/2021.

** Estudante de graduação em Direito pela Universidade Federal de Minas Gerais, foi monitor do grupo de estudos Casa Verde durante o ano de 2020. Possui interesse por Teoria do Estado, Estratégia e Política. ORCID: https://orcid.org/0000-0003-0955-1231. Contato: icarodelrio@gmail.com
} 
raise the material conditions of workers so that they can survive through lawful means. The exception are acts of racism, sexism and homophobia that cut across all social classes. In this case, it calls for the punishment of these conducts, given their impunity, as well as the creation of an apparatus for the protection of the State. Finally, the party is emphatic in defending the reform of the prison system and of the entire repressive apparatus in defense of human rights.

Keywords: Partido dos Trabalhadores; Criminal agenda; Criminology.

\section{POLÍTICA CRIMINAL PETISTA Y SU CRIMINOLOGÍA (1979-2002)}

Resumen: El objetivo de este trabajo es comprender la política criminal (programa que establece las conductas que deben ser consideradas delitos y las políticas públicas para su represión y prevención) y la lectura criminológica (aprehensión de los principales determinantes de la conducta delictiva) que la sustenta. Para ello, se analizaron los documentos redactados por todo el partido durante el período de 1979 a 2002. Estos documentos trazan cinco ejes principales de la cuestión criminal: (i) "Criminalidad" urbana; (ii) Delitos políticos rurales; (iii) "Corrupción"; (iv) Delitos de odio; (v) Defensa de los derechos humanos y reforma del aparato represivo del Estado. Cuando se lee que la delincuencia es una práctica de cierto estrato privilegiado, el partido denuncia su impunidad sistémica y reclama la investigación y sanción de estas conductas, creando aparatos y reformando los que ya existen para tal fin. Cuando el crimen es leído como un "medio antisocial de supervivencia" de las clases desposeídas, se entiende que la política económica se encarga de presionar a los trabajadores a tal comportamiento y la propuesta principal es elevar las condiciones materiales de los trabajadores. La excepción a esta tendencia son los actos de racismo, sexismo y homofobia que atraviesan todas las clases sociales. En este caso, pide la sanción de estas conductas, dada su impunidad, así como la creación de un aparato de protección del Estado. Finalmente, el partido es enfático en defender la reforma del sistema penitenciario y de todo el aparato represivo del Estado en defensa de los derechos humanos.

Palabras clave: Partido dos Trabalhadores; Política criminal; Criminología.

\section{Introdução}

O objetivo deste artigo é trazer elementos para uma breve discussão sobre a política criminal do Partido dos Trabalhadores (PT) entre sua fundação em 1979 até a chegada à presidência da república em 2002.

Compreende-se que:

(...) Política Criminal - tradicionalmente definida como programa que estabelece as condutas que devem ser consideradas crimes e as políticas públicas para repressão e prevenção da criminalidade e controle de suas consequências - 
aumenta sua densidade semântica ao incorporar o significado contido na definição de projeto governamental $(\ldots)^{1}$

A partir das contribuições do materialismo-histórico dialético, entende-se que esta política criminal se conecta aos objetivos estratégicos do partido que, no limite, é expressão dos interesses materiais de certa classe social. Em relação a tais objetivos estratégicos, aceita-se a constatação de diversos autores ${ }^{2}$ de que, em brevíssima síntese, o PT nasceu com o objetivo estratégico de realizar reformas profundas na sociedade e Estado brasileiros, mas realizou um "giro" estratégico na década de 1990 em que se reduziu a intensidade das reformas almejadas para viabilizar a eleição de Lula à presidência.

A pesquisa que originou este artigo, analisou a íntegra de todas as resoluções e demais documentos produzidos nos Encontros Nacionais (EN) e Congressos Nacionais (CN) do partido até 2002, além dos Programas de Governo (PG), estes últimos formulados pelo PT e sua coligação para as eleições presidenciais de 1989, 1994, 1998 e 2002, todos estes disponíveis no acervo digital do Centro Sérgio Buarque de Holanda da Fundação Perseu Abramo $^{3}$.

Este recorte temporal foi realizado por duas razões. A primeira é que após a conquista da presidência da república a política criminal petista passou a se relacionar com a gestão do executivo federal, sendo que a tese Distribuir e Punir ${ }^{4}$ da professora Carla Benitez já faz densa discussão acerca do tema. A segunda razão foi o exíguo prazo de um ano para conclusão da pesquisa que impôs um limite aos documentos a serem trabalhados.

O objetivo específico da pesquisa era que a partir da leitura dos documentos elencados, pudesse se extrair a política criminal defendida pelo PT durante o período estudado. Pela limitação dos dados primários, procurou-se a política criminal nacional, embora municípios e Estados exerçam papéis cruciais na política criminal.

Toda política criminal se baseia em certa leitura criminológica, aqui entendida como apreensão das determinantes das condutas criminosas. Ressalta-se que esta leitura nem sempre está respaldada na realidade objetiva ou em em estudos científicos e pode se sustentar

\footnotetext{
${ }^{1}$ DIETER, Maurício Stegemann. Política Criminal Atuarial. A Criminologia do fim da história. Curitiba, 2012, p. 3.

2 POMAR, Valter Ventura da Rocha. A Metamorfose: programa e estratégia política do partido dos trabalhadores: 1980-2005. São Paulo, 2005; SECCO, Lincoln. História do PT. São Paulo: Editora Ateliê, 2011; SINGER, André. Os sentidos do lulismo: reforma gradual e pacto conservador. São Paulo: Companhia das Letras, 2012.

${ }^{3}$ Link de acesso ao acervo: https://fpabramo.org.br/csbh/acervo-historico-2/

${ }^{4}$ BENITEZ MARTINS, Carla. Distribuir e Punir? Capitalismo dependente brasileiro, racismo estrutural e encarceramento em massa nos governos do Partido dos Trabalhadores (2003-2016). Goiânia, 2018.
} 
tão somente em empirismos e ideias do senso comum. Seja como for, para melhor compreensão da política criminal do PT, buscou-se, igualmente, compreender a leitura criminológica que a fundamentava.

Para tanto, selecionou-se todos os trechos dos documentos em que se debatia alguma forma de crime. Utilizamos a categoria de crime como um processo complexo em que para ser tomada como criminosa certa conduta:

First, it has to be blameworthy and potentially interpreted as illegal. This presupposes the existence of the criminal law. Second, it needs legitimate and recognised actors (usually victims) to define the act as a possible crime and report it to the authorities. Third, there needs to be a normative structure in place to support the definition of the type of act committed by relevant actors as being blameworthy and potentially a crime. Fourth, there needs to be some recognition within the criminal justice system that the claims of the victim and the perceived blameworthiness of the offender are appropriate. In cases in which stages three and four are missing, a 'problematic situation' will not become 'crime', although some form of transgression or victimisation has taken place (Pires and Acosta 1994)..$^{5}$

Vê-se que embora não seja uma categoria estanque, o crime é distinto de outros comportamentos sociais por agregar certo consenso jurídico e social acerca da ilegalidade da conduta, além de ser capaz de mobilizar o Estado para punição da transgressão. Por isso, não selecionamos os trechos em que se utilizava "crime" como adjetivo negativo de certa conduta, embora (como discutiremos na seção "3”) isso não seja sempre claro.

Em seguida, a partir deste levantamento organizou-se os trechos conforme o evento em que foram elaborados (se Encontro Nacional, Congresso, Programa de Governo ou outro) e procurou-se identificar eventuais regularidades ${ }^{6}$ que pudessem ser consideradas como uma posição característica em sua política criminal e leitura criminológica e a partir disso notar eventual variação temporal em tal política.

Como resultado, pretende-se demonstrar que a política criminal petista extraída de seus documentos entre 1979-2002 se organiza em cinco grandes eixos: 1. Criminalidade urbana; 2. Crimes políticos rurais; 3. "Corrupção"; 4. Criminalização das opressões e 5. Direitos humanos e reforma dos aparelhos repressores do Estado. Ao longo deste artigo, iremos discutir os resultados obtidos em seções divididas conforme cada um destes eixos identificados.

\footnotetext{
${ }^{5}$ MATTHEWS, Roger. Realist Criminology. Nova Iorque: Palgrave Macmillan, 2014a. E-book.ISBN 978-1137-44571-1., p. 64.

${ }^{6}$ Por diversas vezes, algumas políticas criminais e aspectos criminológicos são mencionados em um documento e não mais retomados, o que não permite a caracterização de uma tendência.
} 
Além disso, argumenta-se que, a partir dos dados coletados, a característica elementar da política criminal petista é a utilização do direito penal conforme os interesses dos trabalhadores, punindo aquelas condutas das classes dominantes que prejudicam os trabalhadores, mas assegurando meios "sociais" de sobrevivência aos trabalhadores, para que não recorram aos crimes.

A exceção notada a esta tendência ocorre nos crimes contra minorias sociais, como será exposto, pois nestes casos embora o preconceito de raça, gênero e sexualidade atravesse toda a sociedade, a persistência da violência e a sua impunidade requerem a efetiva punição e reforma dos aparelhos.

O partido também irá sempre defender uma política criminal e de segurança pública calcada no respeito aos direitos humanos e por isso advogará a reforma das prisões, da Lei de Execuções Penais e das polícias.

Finalmente, cumpre registrar que apesar de variar conforme o tipo de crime e o momento da escrita, os documentos estudados, via de regra, não debatem longamente acerca de problemas criminais, dedicando-se à maior parte dos textos à análises de conjuntura política e econômica e propostas para tais áreas. Por isso, não são precisas as análises criminológicas e consequentemente o programa criminal é lacônico, geralmente apenas indicando quais condutas devem ou não serem punidas. Dos documentos do partido, só se pode extrair as linhas grossas que orientavam a leitura da realidade criminal e as políticas para saná-las.

\section{1 "Criminalidade urbana"}

O Partido dos Trabalhadores surgiu no final da década de 1970, fruto de um processo de reação da classe trabalhadora à ditadura militar brasileira. Os estudiosos sobre o partido tendem a considerar, esquematicamente, que três grupos se destacaram nesse momento: (i) as franjas progressistas da Igreja Católica que se opunham ao regime e se filiavam à teologia da libertação; (ii) ex-militantes da luta armada e (iii) os operários do novo sindicalismo ${ }^{7}$. Embora o partido aglutine um leque amplo de grupos opostos à ditadura

\footnotetext{
7 "Os primeiros estudos e memórias sobre o PT sacramentaram a visão de um partido constituído por três fontes: a igreja progressista, os remanescentes dos grupos da luta armada e o novo sindicalismo. (...) Desdobrando aquele tripé, poderíamos dizer que o PT surgiu de pelo menos seis fontes diversas. A primeira foi o chamado novo sindicalismo; a segunda, o movimento popular influenciado pela Igreja Católica; a terceira, políticos já estabelecidos no MDB; a quarta, os intelectuais com origens diversas, como o antigo PSB ou posições liberais radicalizadas; a quinta, militantes de organizações trotskistas; a sexta, remanescentes da luta armada contra a ditadura (embora seja possível agrupar estes dois últimos)." SECCO. História do PT, cit., p. 26-27.
} 
militar, vê-se que sua base era composta por trabalhadores brasileiros, e o seu programa geral irá refletir os interesses desta classe social.

No âmbito criminal, a ideia força que irá guiar a leitura criminológica mais ampla durante todo o período entre 1979-2002 nos programas do PT é a correlação entre a "criminalidade" e as más condições materiais dos trabalhadores. Mas esta "criminalidade" não é o conjunto de todas as condutas criminosas praticadas no país, mas aquelas condutas que ocorrem especialmente nos centros urbanos, que comumente envolvem o uso da violência, que são altamente estigmatizadas e que prejudicam principalmente os trabalhadores.

Variando a forma da redação, esta mesma ideia aparece nas resoluções do IV (1986) e do XII (2001) Encontros Nacionais, bem como nos Programas de Governos de 1989, 1994, 1998 e 2002. A formulação mais clara desta linha interpretativa aparece no Plano de Ação Política e Organizativa do Partido dos Trabalhadores Para o Período 1986/87/88, escrito no IV EN:

10. Além das classes trabalhadoras, vêm tendo crescente presença na estrutura social brasileira, principalmente nas cidades, camadas marginalizadas que não encontram lugar no mercado de trabalho ou dele são expulsas, tanto pelo desemprego estrutural quanto pelo conjuntural, que sofreu grande elevação nos últimos anos. Essas camadas marginalizadas de trabalhadores, não conseguindo entrar ou reentrar no mercado de trabalho urbano ou rural,_acabam engrossando o banditismo, a prostituição, a violência, o tráfico de drogas e outras formas anti-sociais de sobrevivência, cujas principais vítimas são os próprios trabalhadores assalariados e as camadas inferiores da classe média. (destaquei)

Esta interpretação criminológica é comum aos marxistas e influencia os partidos de esquerda em todo o mundo. Como este trecho destaca, a "criminalidade" contrapõe trabalhadores que exercem esta forma "anti-social de sobrevivência" daqueles que são vítimas destes crimes.

Esta "criminalidade" é, via de regra, um conflito intra-classe e atinge interesses materiais dos trabalhadores que são vítimas destas condutas. Em crítica às criminologias liberais, Roger Matthews aponta que crimes não são meras "construções sociais" desprovidas de raízes na materialidade:

(...) nos encontramos a quienes niegan que el crimen sea una 'realidad ontológica', gravitando hacia una concepción relativista o posmoderna o hacia un desenfrenado idealismo que califica el concepto del crimen como una mera interpretación subjetiva o manipulación política. ${ }^{8}$ (destaquei)

\footnotetext{
${ }^{8}$ MATTHEWS, Roger. Realismo Crítico: un análisis estructural. Política Criminal, [S.L.], v. 9, n. 17, p. 182212, 2014a. Disponível em: http://dx.doi.org/10.4067/s0718-33992014000100006.
} 
Young $^{9}$ alerta que a ideia de que a classe trabalhadora é simplesmente manipulada pela mídia e outros aparelhos ideológicos a ter pânico da "criminalidade", como se fosse uma folha em branco, é uma visão idealista que ignora o alicerce material das preocupações imediatas dos trabalhadores.

E é nesse sentido que a criminalidade é interpretada no programa petista, reconhecendo que interesses dos trabalhadores são afetados por condutas criminosas e buscando dar soluções concretas a este problema. É evidente que a indignação do trabalhador de ver seus interesses imediatos atingidos é explorada pela indústria midiática com programas sensacionalistas que atravessam as tardes e as manhãs das televisões, estampam manchetes e são alvos de reportagens nos telejornais. Cria-se, nos termos de $\mathrm{Schmitt}^{10}$, um inimigo que está entre nós e deve ser combatido a todo tempo. A ordem constrói sua narrativa, sua ideologia, ao redor de uma contradição que não é a principal, atribuindo ao desvio moral do outro a causa dos nossos males. Contudo, esta inimizade não é criada apenas pelos aparelhos ideológicos, mas partem da realidade material dos trabalhadores para construírem a ideologia de um inimigo:

It is a simple fact that the majority of working-class crime is intra- and not interclass in its choice of target, area of activity and distribution. Working-class people suffer from crime, confront daily the experience of material desperation, undergo the ravages of disorganization and competitive individualism. The ideology that plays on this - bourgeois ideology - contains an element of truth, and touches on the genuine interests of the class - albeit in a distorted fashion. ${ }^{11}$

A política criminal proposta a partir desta leitura criminológica é negativa e propositiva, considerando que tanto os criminosos quanto as vítimas são trabalhadores. $\mathrm{O}$ aspecto negativo é a denúncia da truculência policial que atinge principalmente jovens negros, a aplicação desigual das punições entre classes e a defesa do respeito aos direitos humanos, como trataremos na seção 5. No Programa de Governo de 1989:

...é difícil encontrar numa prisão alguém condenado pelos 'crimes de
colarinho branco' ou por corrupção na máquina estatal. (Destaquei)
Nas últimas décadas, as práticas ilegais cresceram em todas as camadas da
população. A sonegação de impostos, a burla da legislação trabalhista, a
exploração predatória dos recursos naturais nunca foram tão difundidas, impunes
e socialmente legitimadas no Brasil. Mas a noção de crime divulgada pela
imprensa e aceita pelo Estado é quase tão-somente aquela que incrimina os
pobres (crimes contra o patrimônio), esquecendo completamente as
contravenções que ajudam a acumular capital. Essa situação determina a

${ }^{9}$ YOUNG, Jock. Working-class criminology. In: TAYLOR, Ian; WALTON, Paul; YOUNG, Jock. Critical Criminology. Londres: Routledge \& Kegan Paul Ltd, 1975. p. 63-94.

${ }^{10}$ SCHMITT, Carl. Political Theology. Chicago: University Of Chicago Press, 2004.

11 YOUNG. Working-class criminology, cit., p. 79. 
estrutura e o funcionamento de todo o aparato policial, bem como seu relacionamento com as diversas classes sociais. Como consequência, a desigualdade do sistema punitivo é flagrante. A condenação tem sido, entre nós, um amargo privilégio dos pobres, que constituem praticamente toda a população carcerária. (Destaquei.)

Portanto, as propostas para redução desta criminalidade urbana passam a ser a redução do desemprego e a melhoria das condições materiais de vida, sendo a palavra de ordem para a política de segurança pública a ideia de que é melhor e mais razoável "(...) dar um emprego para cada brasileiro do que uma cela para cada desempregado.” (PG/1989).

A principal crítica que se faz a esta leitura criminológica comum aos partidos de esquerda ao redor do mundo é o seu mecanicismo que não consegue explicar porque em certos momentos históricos em que se observou certa melhoria das condições materiais dos trabalhadores, não se constatou respectiva redução dos índices de criminalidade, como posteriormente iria acontecer nas próprias gestões petistas da União ${ }^{12}$.

Aliado a isto, vemos que não se distingue bem e tampouco se procura entender as diferentes causas entre os da "criminalidade" urbana (comumente compreendidos como roubo, furto e homicídios) apoiando-se nas noções vindas do senso comum.

Desta forma, embora seja positivo o reconhecimento dos interesses colidentes de classe (o que se contrapõe ao discurso belicista dos meios e partidos conservadores) no funcionamento da criminalidade urbana, a leitura criminológica do PT é, neste eixo, simplista e por isso mesmo não conseguem formular uma política criminal robusta para a criminalidade urbana.

\section{$1.1 \mathrm{O}$ empresário do crime}

Durante a década de 1990 a análise da questão da criminalidade urbana e consequente programa criminal petista foi sensivelmente alterada. A partir de então ${ }^{13}$, acrescentou-se à política criminal para a "criminalidade urbana" o combate ao narcotráfico e às organizações criminosas, distinguindo o empresário "do crime", que deveria receber o tratamento penal, do consumidor (notadamente jovens) que deveriam ser tratados medicamente, no mesmo discurso que sustentaria os Estados Unidos em sua "Guerra às

\footnotetext{
${ }^{12}$ Ver BENITEZ MARTINS. Distribuir e Punir?, cit.

${ }^{13}$ A repressão ao tráfico de drogas e ao crime organizado aparece pela primeira vez no PG de 1994. Após reaparece nas resolução do X EN (1995), resolução do CN (1999) e nos outros dois PGs (1998 e 2002).
} 
Drogas"14. No programa de governo de 1994 (Bases do Programa de Governo), Capítulo II, item 13 Juventude:

Muitos jovens estão envolvidos com o tráfico de drogas ou são consumidores de drogas ilegais. Entre as iniciativas imediatas, o governo deve inverter a lógica que é trabalhada hoje pela sociedade e pelo Estado. Em vez de preconceito e repressão, a questão da droga deve ser tratada como um problema de saúde pública, oferecendo-se serviços de atendimento, orientação e reinserção aos dependentes. (...) PROPOSTAS (...) Violência 1. Reprimir os narcotraficantes, grandes organizadores do comércio da droga, potencializando o papel dos órgãos de fiscalização e investigando devidamente seu financiamento e suas riquezas ilícitas. (...)

O combate ao crime organizado tem sido nitidamente insuficiente. A prioridade é dada à luta contra os crimes contra a vida e a propriedade. (Destaques meus). ${ }^{15}$

Em 1999 no II Congresso do partido os petistas aprovaram uma resolução específica para tratar o crime organizado no afã da Comissão Parlamentar de Inquérito (CPI) sobre Narcotráfico no Congresso Nacional. Trazem-se aqui os trechos que consideramos decisivos:

\begin{abstract}
A sociedade brasileira está estarrecida. O nosso povo está pagando hoje um alto preço pela política nefasta do neoliberalismo e tantos anos de dominação capitalista em nosso país. A violência vem tomando conta de nossa sociedade e a sua face mais cruel atinge principalmente os mais pobres e deserdados, exatamente a maioria do povo trabalhador brasileiro. As privatizações irresponsáveis, o desmonte do Estado, a centralização tributária no governo federal e uma política de segurança pública errada e ineficiente, que não atende aos interesses da cidadania, vêm deixando os estados desarmados e incapazes de fazer frente ao crescimento da violência, da impunidade e do crime organizado. $\mathbf{O}$ governo de Fernando Henrique foi simplesmente omisso. FHC deixou o país à mercê do narcotráfico e permitiu o crescimento da influência do crime organizado. Sem uma política de segurança séria em nível nacional, proporcionou o crescimento da corrupção grassando nos aparelhos policiais civis e militares. (...) O tráfico de drogas enraizou-se na sociedade brasileira, desde as camadas mais pobres e excluídas até o topo das elites financeiras e do poder econômico. Contaminou o aparelho policial, envolve o Judiciário e faz parte da cena política institucional tanto no Legislativo como em cargos executivos. (...) Como se consolidou este quadro? Fatores vários podem ser arrolados neste diagnóstico. Em primeiro lugar o agravamento da crise econômica e social é responsável direta pelo envolvimento de jovens pobres, sem oportunidades de escola, emprego, vítimas fáceis da sedução da criminalidade associada ao comércio de drogas. Em segundo e decisivo plano está o fato de que o narcotráfico não é uma atividade criminal qualquer. É principalmente um negócio altamente lucrativo, de um mercado em expansão, promissor e que oferece 'oportunidades' de sobrevivência e negócios para um crescente continente de pessoas. Portanto, numa sociedade capitalista, combater o
\end{abstract}

\footnotetext{
${ }^{14}$ OLMO, Rosa del. A Face Oculta da Droga. Rio de Janeiro: Revan, 1990, p. 37.

15 No X Encontro Nacional, em 1995, no tópico "A defesa da Nação": "41- Respeitadas as identidades e soberanias nacionais, são urgentes iniciativas nacionais para (...) combate ao crime organizado, sobretudo o narcotráfico e, especialmente, o enfrentamento dos problemas da exclusão e da pobreza e em defesa do emprego." (destaquei). No PG de 1998 (Diretrizes de Governo: Um Brasil para os brasileiros) também aparece como prioridade o “...combate à corrupção, ao crime organizado e à violência.” (Destaquei).
} 
narcotráfico é antes de tudo combater um ramo do mercado, ou seja, enfrentar as leis do mercado, o que, convenhamos não é tarefa fácil. Os negócios das drogas constituem uma extensa rede que começa do pequeno traficante nas periferias das cidades e acaba no grande negócio da lavagem de dinheiro que usa o sistema financeiro, turismo, jogos de azar, negócios imobiliários, empresas de transporte, além de outras atividades que se tornam vulneráveis à legalização de recursos originados no narcotráfico. (...) (Destaquei)

Esse trecho é uma síntese da caracterização e conjunto de propostas que o PT desenvolveu durante a década de 1990 acerca do crime organizado e do narcotráfico. Retoma a simplista leitura de vinculação direta das mazelas materiais sociais à criminalidade, destacando o papel do neoliberalismo e do desmonte do Estado nesse processo. Como aponta Pomar $^{16}$, durante a década de noventa, o PT alterou a crítica explícita ao capitalismo pela crítica ao neoliberalismo que se tornou hegemônico no país durante a década. Assim, a compreensão de que o neoliberalismo era a determinante primária pela baixa qualidade material de vida da maioria do povo e, logo, causaria o aumento da criminalidade, inclusive a organizada, se consolidou durante a década.

Mas o "crime organizado" acrescenta um novo elemento na leitura da criminalidade urbana: o seu caráter empresarial, lucrativo, e proximidade com o poder do Estado. Até a década de 1990 a questão da criminalidade urbana era preponderantemente lida como um conflito intra-classe e por isso o partido não defendia uma política criminal que punisse mais trabalhadores. Mas, porque existe no topo da cadeia do tráfico de drogas empresários de um ramo sangrento, o partido passa a defender fim da impunidade dos grandes traficante e reforma do Estado para tanto, mostrando a maleabilidade tática do uso do direito penal conforme a classe do agente.

O partido também demonstra que uma situação complexa iria requerer uma gestão complexa. No Plano de Governo de 2002:

37. Diante do crescimento assustador da violência, que tem levado à consolidação, no cotidiano da população, da banalização da vida e da arquitetura do medo, o país necessita, mais do que nunca, de uma política nacional de segurança pública, priorizando a segurança da cidadania na qualidade de direito. Um amplo programa de combate à violência, ao narcotráfico e ao crime organizado supõe uma nova concepção de segurança pública, envolvendo planejamento, definição de metas e estratégias, investimentos em qualificação técnica e profissional e incluindo a integração do sistema policial e uma completa revisão do código penal e do sistema prisional (inspirado por penas alternativas). Deve ganhar destaque não apenas a repressão, mas a prevenção da violência. Dada, afinal, a divisão de atribuições, tal política não poderá prescindir da parceria com estados e municípios.

\footnotetext{
${ }^{16}$ POMAR. A Metamorfose, cit., p. 148.
} 


\section{Crimes políticos rurais}

Se um mensageiro descesse do céu e garantisse que minha morte ajudaria a fortalecer nossa luta, ela até valeria a pena. Mas a experiência nos ensina o contrário. Não é com grandes funerais e manifestações de apoio que iremos salvar a Amazônia. Eu quero viver. (Destaquei, Chico Mendes ${ }^{17}$, militante petista, em carta escrita um ano antes de sua execução.)

Estudar os casos de execuções em conflitos agrários é inquietante. Escolhemos este trecho da carta de Chico Mendes apenas para ilustrar a seriedade da questão. Chico Mendes, um dos mais notáveis militantes extrativistas da nossa história tinha certeza de seu assassinato diante da frequência deste tipo de crime e a quase certeza de sua impunidade. José Batista ${ }^{18}$ apresenta o seguinte dado sobre o sul/sudeste do Pará, uma das zonas de conflito agrário mais intensas do Brasil:

Dentre os 36 municípios que compõem as regiões sul e sudeste do Pará, onde concentra a maioria absoluta dos crimes, apenas dez (Rio Maria, Redenção, Curionópolis, Parauapebas, Eldorado do Carajás, Rondon do Pará, Itupiranga, São João do Araguaia, Nova Ipixuna e Marabá), não possuem taxa de $100 \%$ de impunidade em relação aos assassinatos de trabalhadores rurais nos últimos quarenta e quatro anos (1971-2015). Um município como Xinguara, com 140 assassinatos de trabalhadores rurais nesse período, ainda não teve nenhum crime definitivamente julgado. Isso representa uma taxa de impunidade de $100 \%$. (Destaquei)

Ou seja, em algumas regiões a impunidade em relação ao assassinato de camponeses é garantida. Não é nosso objetivo aqui adentrar na complexa, rica e instigante questão agrária brasileira, ainda que os crimes no campo sejam apenas momentos deste complexo. Iremos apenas apontar em linhas grossas a leitura petista e suas propostas de intervenção.

Desde a sua fundação, o PT denuncia a violência contra trabalhadores no campo e a palavra de ordem presente em quase todos os documentos, em especial as moções, é: justiça por.... A reivindicação do fim da violência no campo, fim da impunidade no campo e moções de solidariedade por trabalhadores rurais assassinados aparecem no III, IV, VI, VII, VIII, IX, X, XI, XII Encontros Nacionais, no Encontro Nacional Extraordinário em 1998, nos programas de governo de 1989, 1994, 1998 e 2002. Independente do momento, essa não cessou de ser uma palavra de ordem, pois, como dito, o poder do latifúndio se preservou e a correlação de forças ainda era desfavorável aos trabalhadores do campo.

\footnotetext{
17 Para ter acesso à carta na integra: https://fpabramo.org.br/2018/12/18/chico-mendes-vive-30-anos-doassassinato-do-protetor-das-florestas/

${ }^{18}$ AFONSO, José Batista Gonçalves. O Massacre de Eldorado dos Carajás e a Luta do Movimento Camponês Pela Terra no Sul e Sudeste do Pará. Marabá, 2016, p. 135.
} 
O PT como expressão política dos trabalhadores brasileiros era no período estudado uma das organizações que aglutinavam camponeses ou era a sua referência política. É exatamente por isso que vários militantes do PT são cabras marcados para morrer.

Temos, neste momento, dezenas de dirigentes, militantes e até mesmo candidatos do PT ameaçados de morte, alguns, inclusive, sendo caçados por matadores profissionais nos sertões de Goiás, Maranhão, Pará, Mato Grosso e outros estados. Existem listas regionais de 'cabras marcados para morrer', elaboradas pelas organizações patronais de direita, nas quais figuram nomes de expressivas lideranças petistas. (Destaquei, Resolução do IV Encontro Nacional, 1986)

José Batista ${ }^{19}$ chama atenção para dois elementos cruciais deste tipo de violência, seu caráter terrorista e seletivo:

\begin{abstract}
Nas três décadas e meia de registro de assassinatos no campo feito pela CPT no sul e sudeste do Pará, chamou a atenção, o grande número de assassinatos de lideranças no período. A violência dos latifundiários, além de ter como objetivo espalhar o medo, o terror (chacinas, queima de corpos, dilaceramentos, excesso de tiros, etc.), tinha também um caráter seletivo. Eliminavam-se as lideranças com o objetivo de desarticular as organizações dos posseiros e dos sem-terra ou suas redes de apoio. (Destaquei)
\end{abstract}

Estes elementos mostram que a violência no campo é qualitativamente diferente da violência urbana, pois marca uma operação tática de um grupo político específico. O conflito entre camponeses e latifundiários, do qual tais execuções fazem parte, não é um conflito intra-classe, como no caso da "criminalidade" urbana, mas entre classes distintas e cujo objetivo é imediatamente desmobilizar a classe dos trabalhadores. No campo, o que depreendemos é que os assassinatos se integram explicitamente a um plano maior, a objetivos estratégicos de certa classe social.

No caderno da Reforma Agrária do PG/1989 os petistas apontam a longa trajetória da violência no campo como marca de toda a nossa história, colonial e escravocrata, agravada no governo militar de Figueiredo pela criação de órgãos de repressão como o Ministério Especial de Assuntos Fundiários que era dirigido pelo secretário-geral do Conselho de Segurança Nacional e o Grupo Executivo de Terras do Araguaia-Tocatins.

Neste mesmo documento, o PT avança evidenciando que no campo o exercício do poder nem sempre é mediado pelo poder econômico através do Estado, quer dizer, há uma “confusão entre o público e o privado", o que facilita este cenário de guerra em que a naturalização da efusão de sangue torna questionável a existência de qualquer ordem 19 AFONSO. O Massacre de Eldorado dos Carajás e a Luta do Movimento Camponês Pela Terra no Sul e
Sudeste do Pará, cit., p. 133. 
jurídica. O trecho deste documento (Caderno de Reforma Agrária, PT/1989) a seguir é um resumo excelente do diagnóstico do partido:

Com a formação da Nova República, em 1985, o Estado se retraiu. Onde se via a atuação direta do Exército ou de outros órgãos federais, apareceram as polícias militares dos estados, aliadas a pistoleiros ou a milícias particulares de latifundiários. A violência contra os trabalhadores não cedeu, como se poderia esperar. Os dominantes continuaram os mesmos, houve apenas uma descentralização no exercício do poder. Enquanto houver latifúndio, em vastas regiões o poder local estará baseado nele. Os trabalhadores sem terra e os posseiros passaram a enfrentar não o inimigo distante, que funcionava a partir das ordens de Brasília, mas o inimigo próximo, que conhece todos os caminhos. O dono da terra também é dono do posto de gasolina, tem um sobrinho no cartório, colocou uma enteada no posto telefônico, influiu na escolha do delegado de Polícia, janta regularmente com o juiz e o promotor. Poder público e particular se confundem. Não é claro onde termina a ação do Estado e começa a da milícia. Não é claro quem faz as leis e quem pode executá-las. Por isso, a imensa maioria dos assassinatos de trabalhadores rurais não ultrapassa a fase do inquérito policial. Por trás dos 496 assassinatos ocorridos desde $1985 \mathrm{em}$ consequência de conflitos de terras ou trabalhistas, há uma articulação de milícias armadas por latifundiários, particularmente nas áreas de fronteira agrícola. Não se trata mais do jagunço antigo, criado na fazenda e, nas horas certas, convocado para fazer o trabalho sujo. Agora são os pistoleiros de aluguel. No início, atuavam individualmente. Com o aumento dos conflitos, se organizaram em grupos que oferecem serviços no mercado da morte. Com a formação de grupos permanentes, aparecem gastos e necessidades permanentes. Manter uma tropa, ainda que reduzida, implica alto custo em equipamentos, armas, munições, veículos e outros materiais. É necessário pagar salários, manter em lugar seguro campos de treinamento, montar esquemas de fuga e esconder elementos 'queimados'. É preciso, ainda, pagar à Polícia taxas de 'convivência', para evitar tropeços. A constituição de grupos paramilitares é por si só geradora de violência. A 'empresa' tem custos e não pode ficar imobilizada. Passa a demandar, ela mesma, serviço. Ao mesmo tempo em que a Nova República se apresentava como a coveira do regime militar, aparecia a União Democrática Ruralista (UDR). (Destaquei)

Apesar do tom desta análise ser mais próprio ao período em que foi escrito (1989, por isso mais radical), durante todo o período analisado os documentos apontam para a necessidade de uma reforma agrária (principalmente como medida econômica) que diluiria o poder do latifúndio e consequentemente diminuir a violência contra os camponeses.

Contudo, além da democratização da terra e do poder no campo, o partido não propõe com regularidade propostas específicas para combate a este tipo de crime.

\section{3 "Corrupção"}

A definição da política criminal petista para os crimes que "vitimam" a administração pública encontra uma dificuldade teórica significativa para a técnica de análise utilizada, pois a palavra "corrupção" é empregada para se referir a uma série de crimes distintos ou à práticas imorais na gestão do Estado que são indesejáveis e/ou ilícitas, 
mas não são necessariamente criminosas. Incompetência, má-fé e crimes acabam se misturando.

Apesar desta dificuldade teórica, a partir do levantamento realizado é possível notar que, em linhas gerais, quando se fala em "corrupção", quer se dizer a utilização por agentes privados do Estado para ganhos privados (o que quase sempre será tipificado como crime pelo Código Penal).

Pelas circunstâncias históricas que discutiremos mais adiante, a partir da década de 1990 o combate à corrupção passa a ser um dos temas centrais nos documentos partidários.

Em um dos seus primeiros documentos, o Tese para atuação do PT (1984), o partido já posiciona o combate à corrupção como prioridade partidária:

\section{(...) assumir as principais bandeiras dos trabalhadores do campo e da cidade, e lutar para acabar com a fome, o desemprego, a miséria, o analfabetismo, os preconceitos raciais, a criminalidade, as epidemias e, em especial, a corrupção. (Destaquei).}

$\mathrm{Na}$ primeira elaboração teórica mais densa sobre o assunto, no Programa de Governo Lula 1989, o PT denuncia o aprofundamento da corrupção no regime militar, uma vez que imprensa e judiciário tinham menos autonomia para fiscalizar o poder executivo. Justamente na transição de regimes e a consequente flexibilização da imprensa, as denúncias de corrupção começam a aumentar. O autoritarismo também facilitaria à corrupção ao tornar o Estado impermeável à participação popular, o que facilitaria a utilização dos recursos públicos para benefício de alguns agentes. Neste mesmo PG, lê-se que "A enorme concentração de poder no Executivo estimula a corrupção, que se alastra como mofo pela máquina do Estado, sem possibilidade de ser combatida pelo remédio da crítica, da denúncia e da punição." (destaquei).

Em 1989, a resolução do IV EN mostrava claramente que o combate à corrupção era tática inserida em uma estratégia de combate à desigualdade:

\footnotetext{
A cara, a marca e os adversários: (...) Tanto Collor quanto Ulysses decidiram levantar a bandeira da moralização como eixo principal de suas campanhas, apesar de não possuírem qualquer base moral para sustentá-las. O PT e os partidos da Frente, por seu turno, embora sejam os que têm as reais condições para sustentar a bandeira da moralidade, por sua coerência de combate à corrupção e aos privilégios, sabem que o que há de mais imoral em nosso país é a miséria das grandes massas da população. A moralidade administrativa é um importante ponto de nossa plataforma política e deve ter o destaque que merece, mas subordinada à nossa proposta e disposição de realizar uma profunda redistribuição de renda e liquidar a miséria, por um lado, e concentração de riqueza, por outro. (destaquei).
} 
Mas a partir da década de 1990, o tema da moralização da administração pública e do combate à corrupção passa a ser muito mais presente nos documentos do partido, aumentando as denúncias de corrupção em diferentes órgãos públicos, a sonegação fiscal e a impunidade dos "escândalos" políticos. Este movimento coaduna com o notado por Pomar de que:

Simultaneamente ao movimento de abandono das classes e da luta de classes como princípio organizador do pensamento e da ação do petismo, outras categorias assumem o papel de organizador geral do pensamento do PT: a ética na política, a solidariedade, o combate à exclusão, o desenvolvimento e a defesa da Nação. ${ }^{20}$ (destaquei).

Esta ênfase parece se associar não só ao distanciamento da prática e ação anticapitalista do petismo descrito por Pomar, mas também ao caráter apelativo que o combate à corrupção possui em nosso país e o impacto positivo que a imagem de "honestidade" em contraposição à “corrupção" possui perante a opinião pública. Singer ${ }^{21}$ aponta que a classe média urbana, mais sensível ao tema, compunha um dos pilares do eleitorado petista até o escândalo do Mensalão em 2005 e a consolidação do lulismo.

Além disso, na década de 1990 o PT se consolidou como o maior partido de esquerda da América Latina e o principal da oposição brasileira, redirecionando energias outrora focadas na militância ao trabalho nos aparatos institucionais e o "modo petista de governar" era importante instrumento de propaganda do partido para galgar posições no Estado:

Ora, em 1994 o partido governava 53 prefeituras (quatro de capitais: Goiânia, Porto Alegre, Rio Branco e Belo Horizonte), tinha 77 deputados estaduais, 33 deputados federais, um senador e 1400 vereadores.

O chamado modo petista de governar significava ética na política, descentralização administrativa, democracia participativa através de conselhos setoriais, mas nada parecido com as propostas de conselhos populares dos anos oitenta. Este modo petista de governar conquistou pelo menos 54 prêmios a prefeituras petistas nos anos $1990 .^{22}$

A ideologia do combate à corrupção possibilita o incendiar da ação política, pois abre portas para a construção do outro a ser combatido, o inimigo, o rosto, que são centrais para que as pessoas despertem o ódio e lutem por algo. Quando o inimigo pode ser visto, quando o inimigo tem um nome ou um cargo torna-se mais fácil mobilizar as massas para combatê-lo, ainda que combatê-lo seja apenas depositar o voto em uma urna.

\footnotetext{
${ }^{20}$ POMAR. A Metamorfose, cit., p. 156-157.

${ }^{21}$ SINGER. Os sentidos do lulismo, cit., p. 102-118.

${ }^{22}$ SECCO. História do PT, cit., p. 162.
} 
Tal combate, em um cenário em que o Estado é ocupado e dirigido quase que em toda a sua totalidade por expressões das classes dominantes, permite que se distinga o "nós" do “eles".Os registros do IX Encontro Nacional deixam isso claro:

É preciso aproveitar cada instante da disputa para mostrar que a miséria cruel distendida sobre o País tem responsáveis, que em geral terminam lucrando com ela. Que existem siglas partidárias atrás de cada escândalo envolvendo PC Farias, ou os anões do Orçamento, as listas do jogo do bicho e todas as negociatas focalizadas pela imprensa. Que o salário mínimo em um patamar vergonhoso de 64 dólares é a fonte dos lucros fabulosos de empreiteiras, bancos e cartéis do comércio e da indústria. (...) 50. Nossa campanha se apoiará, portanto, na afirmação da diferença. Será o confronto da honestidade com a corrupção. (...)

4. Da avalanche de escândalos que soterrou o Governo Collor e manchou a imagem do Congresso Nacional, deixando, com o jogo do bicho, o próprio Judiciário sob suspeita, o PT emergiu como partido de mãos limpas e Lula como candidato de imagem fortemente associada à honestidade. Como é indiscutível, hoje, a sensibilidade do País diante do problema da corrupção, essa diferença torna-se mortal para nossos adversários na disputa. Por isso, sua artilharia visará, precisamente, esse alvo em nossa conduta, inventando, distorcendo, com o objetivo de desfazer essa distinção e nivelar nossa imagem na vala comum dos políticos brasileiros. Daí a importância de empunhar a bandeira da moralidade pública e sair na frente, recuperando todas as ligações detectadas entre nossos adversários e Collor, PC Farias, anões do Orçamento, negociatas, empreiteiras e o crime organizado. Mas, desde o primeiro momento, será preciso aplicar vacinas, imunizando a opinião pública contra as mentiras que os adversários inventarão a nosso respeito. (...)

Este é finalmente o programa de um partido que se mostrou, em toda sua trajetória, incorruptível nas administrações que dirigiu ou dirige, nos parlamentos em que esteve ou está presente. Intransigente a ponto de ficar por vezes isolado, mas sempre ressurgindo como uma referência ética e moral, dentre outras, na sociedade brasileira. (Destaques nossos).

Em síntese das diversas propostas fragmentárias sobre o ponto, as linhas interpretativas que aparecem com mais persistência são as de que a falta de punição e o caráter pouco democrático do Estado causam a corrupção da gestão pública. Como soluções, advoga a efetiva apuração e punição destes crimes e a democratização do Estado calcada, principalmente, na descentralização administrativa e participação popular.

O "corrupto" aparece nos documentos como outro inimigo que deve ser combatido, tais como os grandes traficantes e os latifundiários, ainda que neste ponto o combate se dê não só via prisão, mas também eleições. Existe continuidade com o observado na seção anterior, pois os "corruptos" por não agirem no interesse das classes trabalhadoras (na acepção dos textos descritos) devem ser punidos e derrotados. 


\section{Criminalização das opressões}

O PT funcionou como guarda-chuva da oposição após a ditadura militar, acolhendo dentro do partido vários grupos, movimentos sociais e até partidos, sendo que alguns destes movimentos ou pessoas atuavam em áreas específicas como o combate ao racismo, machismo e a discriminação sexual.

Essa condição subjetiva fez com que o PT incorporasse ao seu programa diversas reivindicações de demandas intra-classes, denunciando certas opressões que atingem setores específicos dos trabalhadores.

Essas demandas históricas incorporadas à política criminal petista são a investigação e punição dos crimes praticados em razão da raça, gênero ou sexualidade da vítima, ainda que a punição à violência racial e de gênero sejam mais presentes.

O VIEN ao fixar as bases para o programa de governo, Lula/89 defendia:

Punição de toda discriminação de sexo, orientação sexual, cor, idade, estado civil no trabalho e aplicação dos direitos trabalhistas integrais das mulheres trabalhadoras, das gestantes, das domésticas e das trabalhadoras rurais."

Em relação à questão racial, o partido denuncia que negros e negras estão submetidos a violências físicas, psicológicas além de serem mais vítimas de assassinatos direcionados ${ }^{23}$. Também demonstra indignação com as execuções promovidas por grupos de extermínio urbanos que vitimaram vários "meninos de rua", geralmente negros, ao longo do período estudado ${ }^{24}$. O reconhecimento da existência do racismo ${ }^{25}$ enseja diversas propostas (em vários âmbitos) no programa petista.

No recorte criminal, o PT propôs e aprovou no Congresso Nacional a Lei 7.716/89 que definiu os crimes raciais no Brasil, além de ter sido fundamental na Constituinte para que se criminalizasse o racismo e o tornasse crime inafiançável, no ano do centenário da abolição, importantes armas ideológicas para os negros e negras no Brasi ${ }^{26}$.

\footnotetext{
${ }^{23}$ Aparece no V EN (1987), I CN (1991), PG (1994), X EN (1995), II CN (1997), XII EN (1999), por três vezes no PG (2002).

${ }^{24}$ Registrado no VI EN (1989), por duas vezes no PG 1994 e Moção no XII EN (2001), PG (1989), I CN (1991), PG (1994).

${ }^{25}$ Apesar de parecer óbvio, é preciso considerar a forte tradição político-ideológica que nega a existência de racismo no Brasil.

${ }^{26}$ Por duas vezes (quer dizer, de forma fragmentária), a manutenção da maioridade penal em 18 anos (X EN de 1995 e XI EN de 2001) e o agravamento de penas contra racismo (PG de 2002).
} 
Já em relação à violência de gênero, o partido compreende que este tipo de crime ocorre, comumente, no ambiente doméstico ${ }^{27}$, ainda que as mulheres estejam submetidas à violências públicas e privadas.

Ao longo dos documentos, sempre clama pela efetiva apuração e punição dos crimes contra a mulher. No PG/2002 até se critica a Lei 9.099/95 que a redação da época, de acordo com o partido, facilitava a impunidade dos agressores de mulheres.

Especificamente advoga a criação de um aparato de acolhimento das vítimas de violência (PGs de 1989, 1994 e 2002). Fragmentariamente, reivindica a alteração do Código Penal (PG 1994), treinamento do aparato policial (PG 1994). No Congresso Nacional do Brasil, o PT propôs e aprovou a Lei 9.046/95 que obrigava que os estabelecimentos penais femininos a terem um berçário e em 2001 também conseguiu aprovar a Lei 10.224/01 que alterou o Código Penal e criou o crime de assédio Sexual.

Uma parte específica, que merece uma pesquisa autônoma, é a posição do PT sobre o aborto. No PG de 1989 o PT propõe um "debate" para que se amplie os direitos à interrupção da gravidez. A partir daquele momento o aborto só aparecia em um programa de governo em 1994, em que se defendia apenas o amparo e atendimento do aborto legal. A descriminalização do do aborto apareceu como moção "de repúdio" no VIII do EN²8 (1993) Vaticano que puniu uma freira que defendeu o direito ao aborto.

Talvez este recuo nos documentos esteja relacionado ao giro estratégico petista, ocorrido na década de 1990, especialmente diante da impopularidade eleitoral do aborto, embora não seja possível inferi-lo apenas dos documentos e bibliografia estudados.

Em relação aos crimes de homofobia, o PT denuncia a gravidade dos crimes motivados pelo ódio aos "homossexuais" (termo empregado nos documentos), propondo-se sua rigorosa apuração e sua criminalização específica no já mencionado PG de 1989, mas também no PG 1994 e XII EN de 2001.

A leitura que se faz é de que estes crimes são motivados pela intolerância e que a impunidade facilita a sua execução.

Vai desde manifestações de intolerância no mundo do trabalho, na família ou no sistema educacional, até o exercício da violência física, responsável, nos últimos dez anos, pelo assassinato de 1.200 pessoas em razão de sua orientação sexual. Os assassinatos de homossexuais, geralmente revestidos de requintes de crueldade, têm ficado na maioria dos casos impunes, uma vez que a própria investigação policial é feita de forma negligente. A impunidade que protege tais crimes é

${ }^{27}$ EN XII de 2001, PGs de 1998, 2002.

${ }^{28}$ A moção é votada a parte das resoluções principais e permite que grupos específicos apresentem redijam uma manifestação que se aprovada integrará os documentos do encontro. 
motivada e reforçada pela disseminação de preconceitos contra homossexuais, aos quais se atribui a disseminação de enfermidades como a Aids e a deterioração de 'valores estabelecidos (...) 1. iniciativas de modificações das leis penais, trabalhistas e outras, tipificando o delito de discriminação por orientação sexual e garantindo a plena igualdade de oportunidades; 2 . medidas policiais de proteção a homossexuais e investigação rigorosa dos crimes contra eles cometidos;' (Destaquei, PG 1994.)

Esta seção demonstra uma fuga na tendência de se reivindicar a criminalização secundária de condutas quando se lê que o criminoso integra a classe dominante, uma vez que a violência contra negros, mulheres e LGBTs é disseminada na sociedade, independentemente de classe, como o próprio partido aponta. $\mathrm{O}$ que, a partir dos documentos, explica a reivindicação da criminalização secundária por vezes atreladas à própria edição de novos tipos penais é a persistência deste tipo de violência e a sua impunidade.

De tal forma, quando o interesse de fortes movimentos sociais, como o negro, feminista e LGBT, colide com práticas sociais insistentemente impunes, o partido advoga a sua punição, reforma do Estado e criação de um aparato de proteção.

\section{Direitos humanos e reforma dos aparelhos repressores do Estado}

O PT surgiu da luta contra a direção militar do Estado brasileiro. Desta forma, durante o período de transição democrática o PT protagonizou a luta por um processo que punisse as violações de direitos humanos dos militares, assim como que se reformassem os aparatos autoritários consolidados no regime.

Em um dos seus primeiros documentos, sua Declaração política de 13/10/1979 o PT conclamava uma “...anistia que atinja todos os perseguidos do regime [militar]", e o “...fim das torturas, investigação de todas as arbitrariedades policiais e punição dos responsáveis" e o “...fim dos tribunais de exceção”. Nessa mesma toada, seguem o Manifesto de fundação e o primeiro Programa do partido que traça a tarefa de se revogar a Lei de Segurança Nacional.

No III Encontro Nacional redigiu-se as Teses para a atuação do PT, em que o partido explicita uma das marcas de seu programa: “O governo do PT aplicará uma política de segurança baseada no respeito aos direitos humanos e que colocará a polícia a serviço, efetivamente, da proteção da população".

A defesa programática de uma política de segurança pública calcada nos direitos humanos é característica dos documentos do PT que mesmo ao tratar de pontos "de 
emergência" (como o crime organizado mostrado anteriormente) argumenta que toda ação deve respeitar os direitos humanos. O termo "Direitos Humanos" aparece mais de cinquenta vezes ao longo de todos os documentos analisados, e está presente em todos os encontros nacionais, congressos nacionais e programas de governo. É por esta defesa que o PT cumpriu papel histórico importante na constituinte no combate à tentativa de implementação da pena de morte no Brasil ${ }^{29}$.

Além disto, denunciava o "calabouço" que são as prisões brasileiras e a necessidade de se reformar nosso sistema carcerário para que ela pudesse cumprir a sua função declarada de ressocialização:

\begin{abstract}
Não pode haver dúvida de que é mais fácil - além de mais razoável - dar um emprego para cada brasileiro do que uma cela para cada desempregado. Que cela! De modo geral, as prisões brasileiras são calabouços fechados, nos quais os presos são submetidos a processos de humilhação e aniquilamento que agridem qualquer sociedade civilizada. A crise do sistema carcerário é evidente e não existem perspectivas a curto e médio prazo para seu equacionamento. (...) Na verdade, a questão penitenciária não pode ser equacionada com a simples construção de novos presídios, na forma tradicional, esquecendo-se o papel fundamental da família e da comunidade na recuperação do detento. (Destaquei, PG/1989.) ${ }^{30}$
\end{abstract}

O partido desde $1986^{31}$ já defendia que a prisão deveria ressocializar os presos e que as condições em que se encontram as prisões brasileiras obstavam este objetivo. Logo, a própria reforma carcerária e a garantia dos direitos humanos dos presos seriam instrumentos de combate à "criminalidade". A reforma das prisões brasileiras, aliadas à reforma da Lei de Execuções Penais, aparecem com notável frequência ${ }^{32}$.

O programa também expressa preocupação com os policiais, reclamando sua qualificação ${ }^{33}$, fornecimento de equipamento adequado ${ }^{34}$ e a sua desmilitarização ${ }^{35}$

A defesa dos direitos humanos atravessa todo o programa petista. No âmbito criminal, vemos que isso conduz à indignação diante dos crimes da ditadura, das execuções dos grupos de extermínio, dos crimes de ódio e do estado permanente de caos das prisões

\footnotetext{
29 Para ver uma reportagem da época sobre o assunto: https://www2.senado.leg.br/bdsf/bitstream/handle/id/124547/1988_01\%20a\%2010\%20de\%20Fevereiro\%20$\% 200084$.pdf?sequence $=1 \&$ isAllowed $=y$

${ }^{30}$ A mesma denúncia aparece no X EN de 1995 e XII EN de 2001.

31 "Fica aprovado o encaminhamento, ao Comitê referido no item anterior, das seguintes propostas: (...) d) reforma presidiária e carcerária, para permitir a recuperação social dos detentos." Trecho das resoluções aprovadas no IV Encontro Nacional que preparou o partido para a Assembleia Nacional Constituinte."

32 Por duas vezes no IV EN (1986), PG (1989), PG (1994), PG (1998), CN (1999), XII EN (2001).

${ }^{33}$ PG (1989), XII EN (2001) e PG (2002).

${ }^{34}$ PG (1994), XII EN (2001) e PG (2002).

${ }^{35}$ PG (1994), XI EN (1997) e ENE (1998).
} 
brasileiras. Por isso, na transição democrática o partido reivindica a apuração e punição dos crimes da ditadura, a apuração e punição dos grupos de extermínio, criação de aparatos de proteção às minorias (discutidos anteriormente) e a reforma do sistema carcerário brasileiro, apontando que, para o PT, a prisão deve cumprir sua função ressocializadora.

Como se sabe, as prisões encarceram predominantemente trabalhadores e por todo o discutido, a defesa de que estes ambientes fossem dignos coaduna com interesses das classes que compunham o petismo.

\section{Conclusão}

A política criminal petista e a leitura criminológica que a embasa demonstra a sua conexão com a sua base social: os trabalhadores brasileiros. Percebemos que as questões levantadas como problemas a serem enfrentados são aqueles que afligem os trabalhadores nas cidades (seja pelo medo de terem seus bens ou seu cotidiano atrapalhados seja pela ineficiência do Estado em lhe assegurar direitos), a vanguarda dos trabalhadores no campo, a administração pública, e as "minorias" que sofrem violências específicas no seio dos próprios trabalhadores, sempre respeitando os direitos humanos.

A identificação das determinantes destes crimes e as políticas para saná-los são lacônicas nos documentos estudados, até porque nestes documentos se debatiam inúmeros outros assuntos cruciais para o PT e o Brasil.

A tendência observada na política criminal/leitura criminológica é a demarcação entre o "nós" e o "eles". Quando se compreende que aquele que pratica o crime integra uma classe privilegiada e que o crime é um meio de obtenção de dinheiro por poderosos, o partido denuncia a impunidade sistêmica desses agentes e conclama, preponderantemente, a punição, criando-se aparatos e reformando os já existentes para tanto. Quando o crime é um "meio anti-social de sobrevivência" das classes espoliadas, compreende-se que a política econômica é a responsável por pressionar os trabalhadores a tais condutas e a proposta principal é elevar as condições materiais dos trabalhadores para que possam sobreviver através de meios lícitos.

Na década de 1990, a proximidade do partido à institucionalidade e o seu giro estratégico parecem ter influenciado na consolidação de uma política de combate à "corrupção" cada vez mais voltada para fins eleitorais, como propaganda política. Neste mesmo período, aumenta-se a preocupação com a expansão do "crime organizado", especialmente o narcotráfico. 
A proposta de criminalização das opressões foge um pouco da tendência observada, pois os crimes de intolerância ocorrem entre trabalhadores e patrões. Assim como nos casos da criminalidade urbana, os crimes de ódio confrontam setores internos à classe trabalhadora e, apesar disso, o PT reivindica a sua efetiva punição, indicando que apesar dos autores não integrarem necessariamente as classes dominantes, quando se entende que a impunidade é essencial à continuidade daquele crime, insere-se no programa a punição destas condutas e o aprimoramento dos aparelhos de Estado para tanto. 


\section{Referências Bibliográficas}

AFONSO, José Batista Gonçalves. O Massacre de Eldorado dos Carajás e a Luta do Movimento Camponês Pela Terra no Sul e Sudeste do Pará. Pará, Marabá, 2016.

BENITEZ MARTINS, Carla. Distribuir e Punir? Capitalismo dependente brasileiro, racismo estrutural e encarceramento em massa nos governos do Partido dos Trabalhadores (2003-2016). Goiânia, 2018.

CAMPOS, Marcelo da Silveira. Crime e Congresso Nacional no Brasil pós-1988: uma análise da política criminal aprovada de 1989 a 2006. São Paulo, 2010.

CHASIN, José. As máquinas param, germina a democracia! In: CHASIN, José. A miséria brasileira: 1964-1994: do golpe militar à crise social. São Paulo: Estudos e Edições Ad Hominem, 2000, p. 79-108.

FUNDAÇÃO PERSEU ABRAMO (São Paulo). Centro Sérgio Buarque de Holanda (comp.). Acervo Histórico. Disponível em: https://fpabramo.org.br/csbh/acervohistorico-2/. Acesso em: 06 abr. 2020.

MATTHEWS, Roger. Realismo Crítico: un análisis estructural. Política Criminal, [S.L.], v. 9, n. 17, p. 182-212, 2014b. Disponível em: http://dx.doi.org/10.4067/s071833992014000100006.

MATTHEWS, Roger. Realist Criminology. Nova Iorque: Palgrave Macmillan, 2014a. Ebook. ISBN 978-1-137-44571-1.

MICHELOTTI, Fernando. Território de produção agromineral: relações de poder e novos impasses na luta pela terra no sudeste paraense. Rio de Janeiro, 2019.

OLMO, Rosa del. A Face Oculta da Droga. Rio de Janeiro: Revan, 1990.

POMAR, Valter Ventura da Rocha. A Metamorfose: programa e estratégia política do partido dos trabalhadores: 1980-2005. São Paulo, 2005.

SANTOS, Juarez Cirino dos. A Criminologia Radical. Curitiba: ICPC: Lumen Juris, 2008.

SCHMITT, Carl. Political Theology. Chicago: University Of Chicago Press, 2004.

SECCO, Lincoln. História do PT. Cotia, SP: Editora Ateliê, 2011.

SINGER, André. Os sentidos do lulismo: reforma gradual e pacto conservador. Paris: Companhia das Letras, 2012.

YOUNG, Jock. Working-class criminology. In: TAYLOR, Ian; WALTON, Paul; YOUNG, Jock. Critical Criminology. Londres: Routledge \& Kegan Paul Ltd, 1975. 
Como citar este artigo: GOMES, Ícaro Del Rio Pertence. Política criminal petista e sua leitura criminológica (1979-2002). Revista de Ciências do Estado, Belo Horizonte, v. 6, n. 2, p. 1-24, 2021.

Recebido em 05.09.2021

Publicado em 08.12.2021 